SB 433

.08 


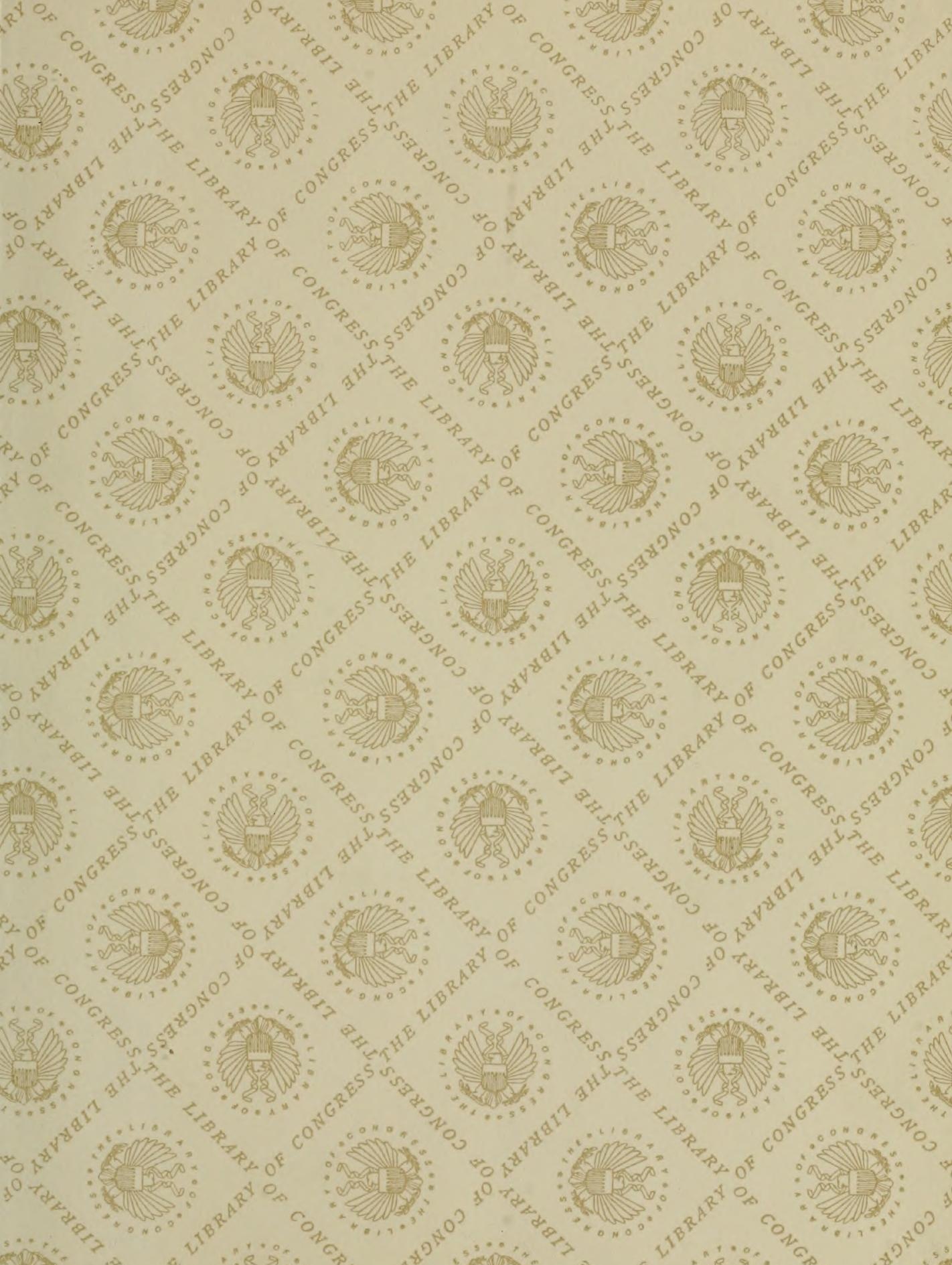





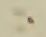



Lawns, Golf Courses,
polofields

By S.A.Cunningham and George D. Leavens

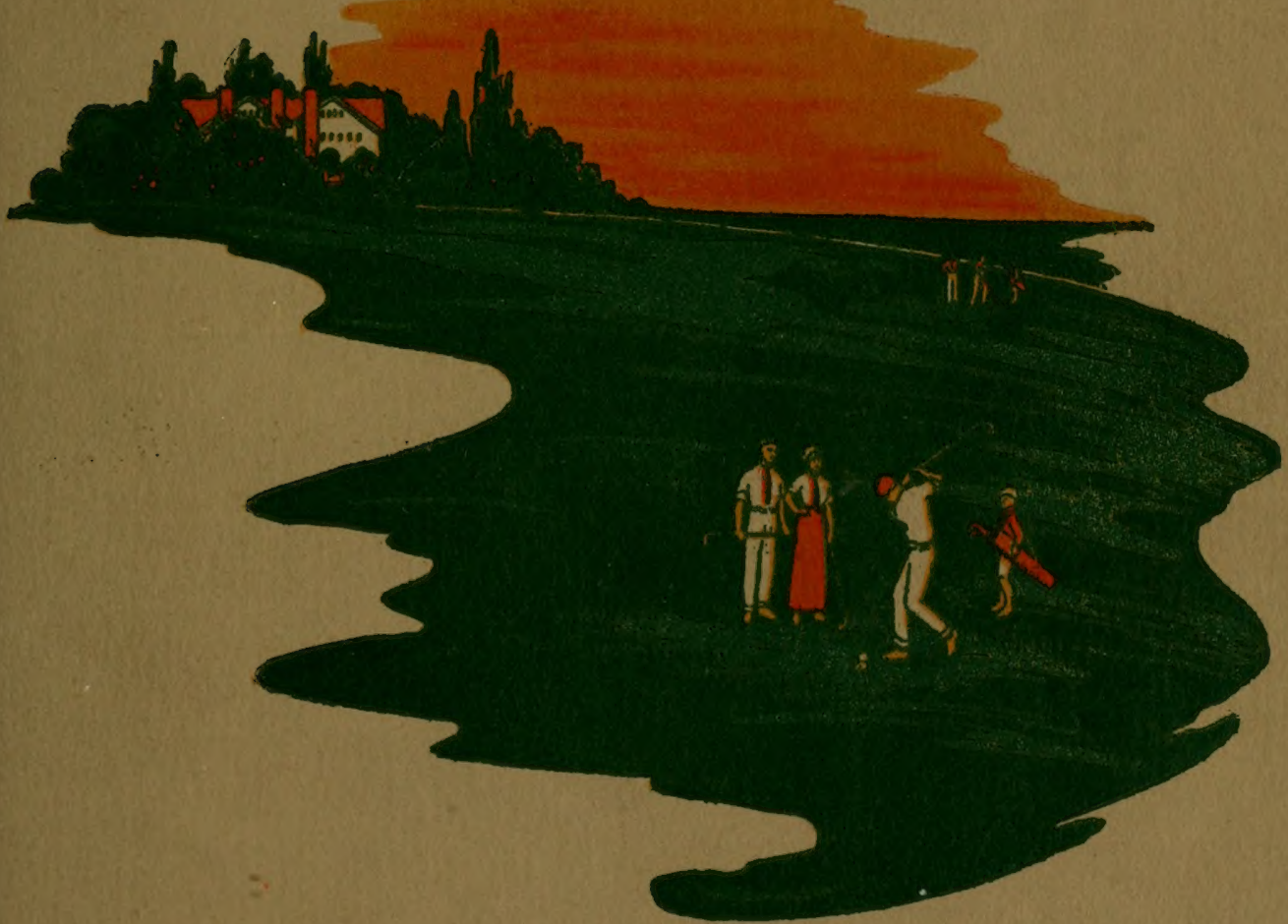

\section{The Coe-Mortimer Company NewYork}





\title{
Lawns, Golf Courses, Polo Fields, and How to Treat Them
}

\author{
By S. A. CUNNINGHAM \\ Chairman of the Green Committee of the Englewood Golf Club \\ and
}

GEORGE D. LEAVENS, B. S.

Formerly of the Department of Fertilizers, Massachusetts Agricultural Experiment Station

Published by

THE COE-MORTIMER COMPANY

New York 


$$
s^{3^{\lambda^{3}}} c^{\infty}
$$

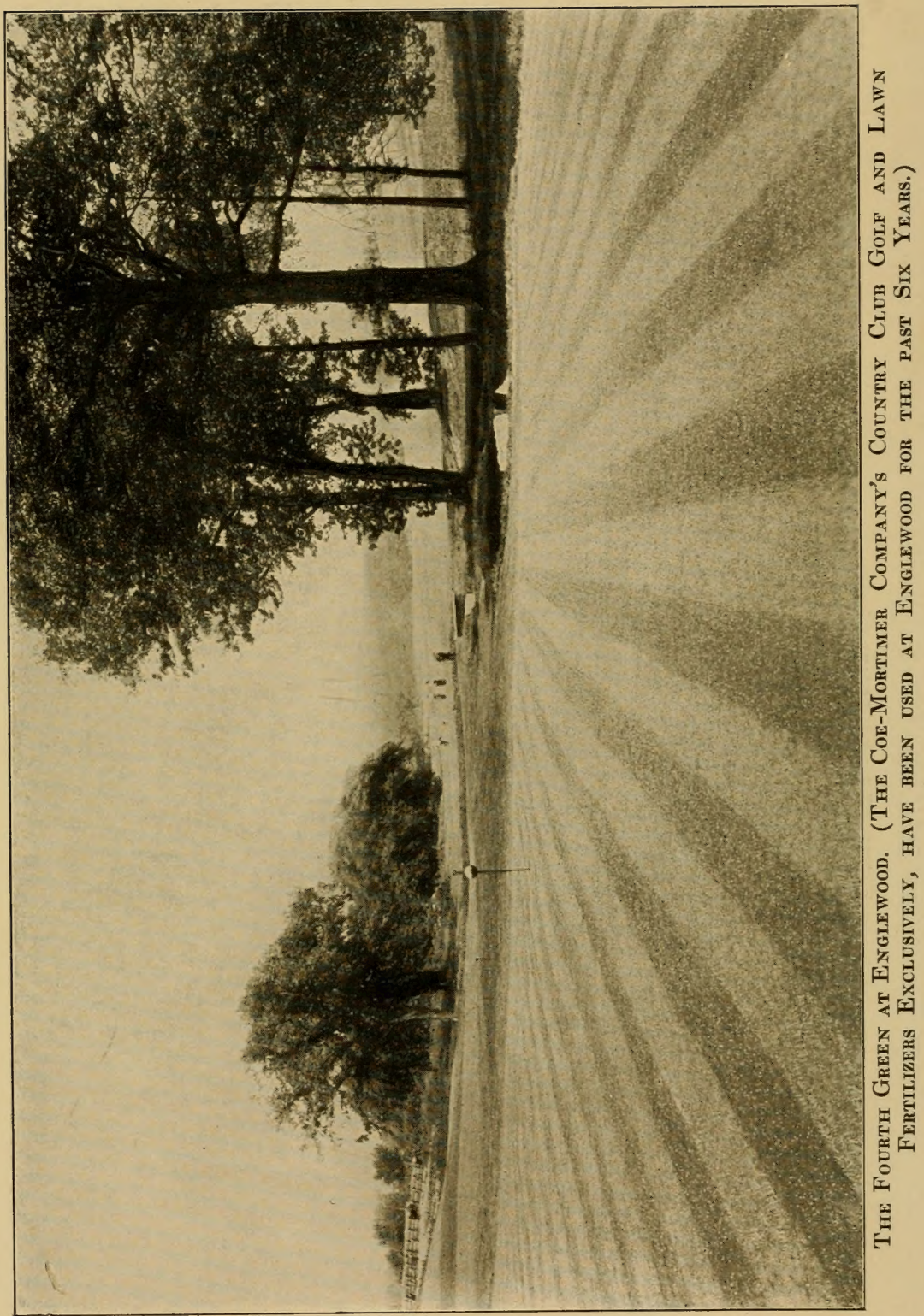

TRANSFERRED FROM

MAR 281914 gOPYRAGHT OFFIOE 


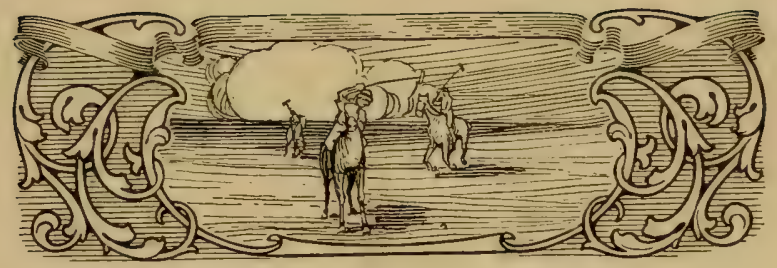

\title{
LAWNS, GOLF COURSES, POLO FIELDS, AND HOW TO TREAT THEM
}

By

\author{
S. A. CUNNINGHAM AND GEORGE D. LEAVENS
}

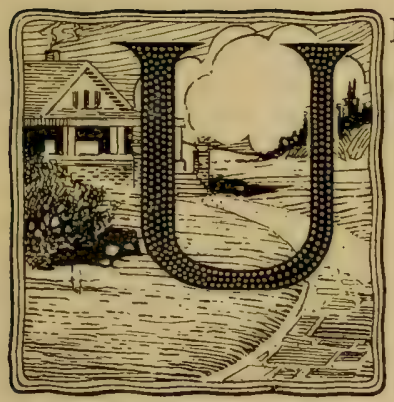

NTIL the attempt has been made, the difficulties encountered in making good lawns, polo fields, or golf greens are not apparent, although liberal sums of money are generally expended for these purposes. There is, however, such a conflict of opinion and such a dearth of definite information as to how desirable results may be obtained, that it is believed that the writers' suggestions, based upon many years of practical experience, may not be unwelcome.

No attempt is made to discuss herein details of engineering problems in connection with the making of golf courses and polo fields, other than a few remarks on the subject of drainage. The details of grading, levelling, tile draining, etc., should all be arranged by a competent engineer. The writers of this booklet have confined themselves strictly to matters covered by their own personal experience, realizing that in so doing they are certain to remain on safe ground and in all probability be of much greater assistance to their readers. 


\section{LAWNS.}

A good lawn is the first essential to a beautiful landscape or to attractive home grounds. The two problems commonly presented in this connection are: first, the improving or re-making of an old lawn; second, the making of a new lawn from the very beginning.

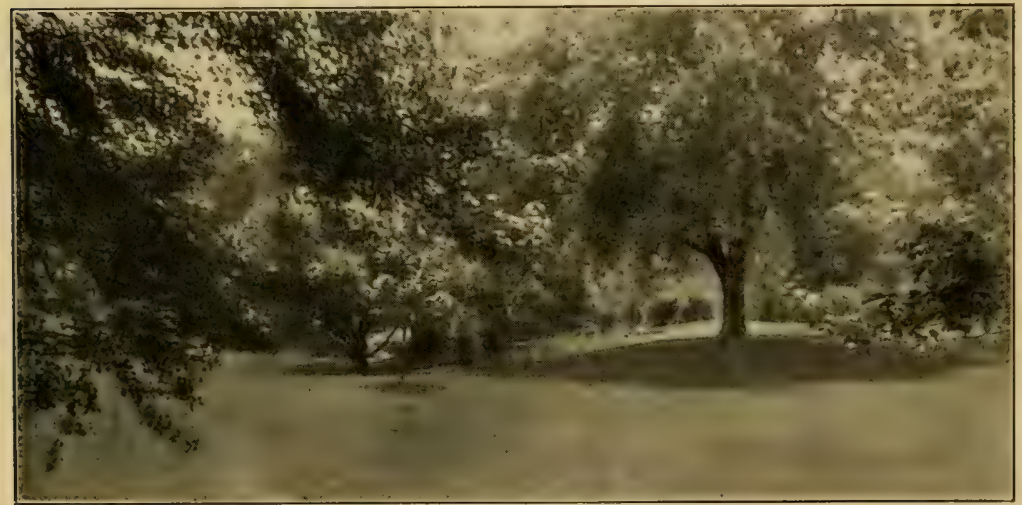

A Good Lawn may be maintained in a Shaded Location yf proper Grass Seeds and Fertilizers are used.

\section{Re-Making an Old Lawn.}

The first step is to dig out with a very slender trowel or stout knife, all the weeds that infest the lawn. The best implement for this is an ordinary asparagus knife or cutter. Having removed the weeds, go over the old lawn vigorously with a sharp toothed iron rake, scratching the earth to a depth of half an inch or more. Where the old sod is vigorous and healthy, rake lightly; but give severe treatment to the bare spots.

A' sod perforator may be made by driving some good-size spikes through a piece of plank, and then attaching to this a handle from an old shovel or manure fork. The spikes should protrude through the plank three or four inches. By going over the lawn with this implement, the soil will be opened up 
to receive grass seed, plant food and moisture, and yet no unsightly disturbance of the surface will be made.

On a large scale (on fair greens and polo fields) the same or better results are obtained by using a perforating roller, to which reference will be made later. In case a sod perforator is used, it should be followed by a vigorous raking, as described above, and if a quantity of fine or medium fine sand can be obtained, this may also be raked over the lawn evenly to the depth of about one-fourth inch.

Next, broadcast The Coe-Mortimer Company's Country Club Golf and Lawn Fertilizer, Brand A, at the rate of two and one-half to three pounds to each one hundred square feet of surface. The fertilizer should be mixed with an equal quantity of medium to coarse sand. Fine sand may be used when the soil is naturally coarse and open, but coarse sand is to be preferred wherever the soil is especially compact and inclined to cake. The sand should be well raked in.

Grass seed should now be sown, carefully raked in, and the land thoroughly rolled. Grass seed mixtures for this purpose are as follows:

First, for use on neutral or alkaline soils where Kentucky Blue Grass grows well. Such conditions are particularly apt to prevail in those parts of the country where the soil is underlaid by limestone deposits. Under such conditions, when renovating the old lawn, use the following mixture:

Re-cleaned Kentucky Blue Grass (Poa pratensis).. 30 lbs.

Re-cleaned Redtop ( $\boldsymbol{\Lambda}$ grostis vulgaris).......... 30 lbs.

Creeping Bent Grass (Agrostis stolonifera)....... 20 lbs.

Rhode Island Bent Grass (Agrostis canina)......... 10 lbs.

Wood Meadow Grass (Poa nemoralis).......... 10 lbs.

Total....................... 100 lbs.

Apply this mixture at the rate of eighty to one hundred pounds per acre. (About one-fourth pound per 100 square feet.)

Mixture Number 2. - Where acid soil conditions prevail, Kentucky Blue Grass will not thrive, and a different mixture of grass seeds must therefore be used. Acid soil conditions 


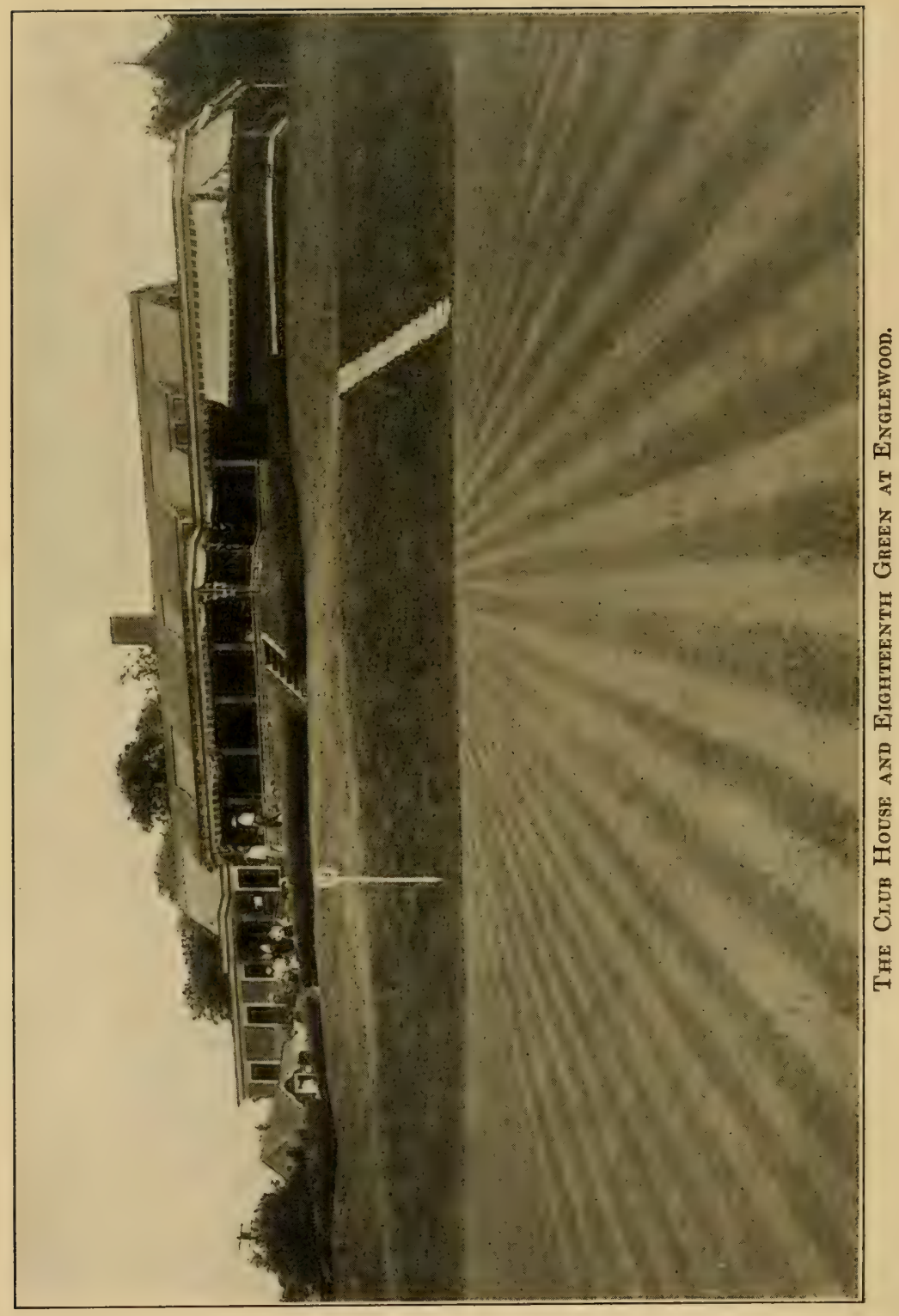


prevail generally throughout most of the Atlantic Seaboard states, and the following mixtures will be found generally useful:

Re-cleaned Redtop (Agrostis vulgaris) .......... 50 lbs.

Rhode Island Bent Grass (Agrostis canina)......... $25 \mathrm{lbs}$.

Creeping Bent Grass (Agrostis stolonifera).......... 25 lbs.

$$
\text { Total....................... } \overline{100} \text { lbs. }
$$

Sow evenly at the rate of 80 to 100 pounds per acre. (About one-fourth pound per 100 square feet.)

After distributing, the seed should be lightly raked in and the lawn thoroughly rolled.

Abundant moisture is necessary for the life of any lawn, and this will be discussed later in the remarks about "watering."

A second application of fertilizer will be needed about August first to August tenth. At that time apply The CoeMortimer Company's Country Club Golf and Lawn Fertilizer, Brand $\mathrm{A}$, at the rate of two and one-half to three pounds per hundred square feet. The fertilizer should be mixed with an equal quantity of sand as previously mentioned.

\section{Making a New Lawn.}

If the work is being conducted on a small scale, the ground should be well spaded up and thoroughly pulverized with a sharp rake. Then rake to a smooth, level surface and follow the same general treatment as that described for large areas.

If large areas are to be treated, it may be necessary to consider carefully the matter of drainage. A competent engineer should be consulted and such stone drains or tile drains as may be needed should be put in place. The best time for making a lawn is from mid-summer to early September and if the necessary work can be accomplished so that the seed can be sown about August fifteenth to September tentli, the grass will get a good start before cold weather.

Frequently howerer, for special reasons, spring seeding is necessary and in this case if possible, the land should be plowed in the fall so that the action of the frost may assist in pulverizing and conditioning the soil. 
Whether spring seeding or summer seeding is to be followed, the general operations necessary for good results are the same. Stones and stumps, if any, should be removed. The entire surface should then be broken up by using a cutaway disc harrow, set at a sharp angle so that it will thoroughly tear up the old surface growth. This harrowing should be repeated at intervals of three or four days until all old growth is entirely killed out and dried up.

The land should then be plowed to a depth of from eight to ten inches and it is important to see that the plow is equipped with a coulter so that all old growth may be completely buried.

After plowing, the land should be harrowed with a cutaway disc harrow. If the land is inclined to bake and cake, coarse sand should now be applied to a thickness of from one-half inch to an inch. This sand should be thoroughly worked into the soil by the subsequent harrowings with the cutaway disc harrow, and these harrowings should be continued at frequent intervals, say every four days, until the time of seeding.

'The fertilizer' should now be broadcasted very evenly. Use The Coe-Mortimer Company's Country Club Golf and Lawn Fertilizer, Brand $A$, at the rate of two and one-half to three pounds per hundred square feet. (On large areas, 1300 to 1500 pounds per acre.) At least two harrowings should be given after the fertilizer is applied.

The heavy cutaway disc harrow should be followed by a smoothing harrow and clod crusher or leveler. It is generally best also, to go over the land with a roller to insure getting a smooth and level surface. Just before sowing the seed the surface of the ground should be finally prepared by going over it once more with a smoothing harrow. The seed should then be distributed evenly and worked into the soil with an ordinary weeder or with an ordinary bush harrow. This latter implement is made by spiking medium sized birch saplings to a piece of $5 \times 5$ or $6 \times 6$ timber; but unless one is familiar with the construction and use of this implement, the weeder had better be employed. 
The land should now receive a thorough rolling. Roll in several directions; at right angles, also diagonally. It is desirable that the soil should be well compacted at this time in order to re-establish capillary action.

For seeding a new lawn, the following mixtures may be used. The first mixture given is suitable for use on neutral or slightly alkaline soils, such as we have previously referred to. Under these conditions use the following mixture per acre:

Kentucky Blue Grass (Poa pratensis)............ 45 lbs.

Rhode Island Bent Grass (Agrostis canina)......... 30 lbs.

Fancy Re-cleaned Redtop (Agrostis vulgaris)....... 45 lbs.

$$
\text { Total, per acre................. } \overline{120} \mathrm{lbs} \text {. }
$$

(A little over one-fourth $1 \mathrm{~b}$. per 100 square feet.) exist.

Second, a mixture to be used where acid soil conditions

Fancy Re-cleaned Redtop (Agrostis vulgaris)..... 4.5 lbs.

Creeping Bent Grass (Agrostis stolonifera)....... 45 lbs.

Rhode Island Bent Grass (Agrostis canina)...... 30 lbs.

Total, per acre.............. $\overline{120}$ lbs.

(A little over one-fourth $\mathrm{lb}$. per 100 square feet.)

A third mixture is given for use in shady places. There are of course some conditions where the shade is so great that no grass will grow, but under conditions of moderate shade, the following mixture will generally prove successful.

Kentucky Blue Grass (Poa pratensis).......... 35 lbs.

Wood Meadow Grass (Poa nemoralis)........... 35 lbs.

Crested Dogs'-Tail (Cynosurus cristatus) .......... 15 lbs.

Various-Leaved Fescue (Festuca heterophylla).... $15 \mathrm{lbs}$.

Total, per acre................. $100 \mathrm{lbs}$.

(On small areas use at the rate of one-fourth $\mathrm{lb}$. per 100 square feet.)

\section{Clipping, Rolling and Watering.}

A newly seeded lawn should not be clipped the first time until the grass has made a good growth. Set the blades of the lawn mower as high as possible. Let the young grass grow so that the mower set in this way will just clip off the ends of the leaves. 


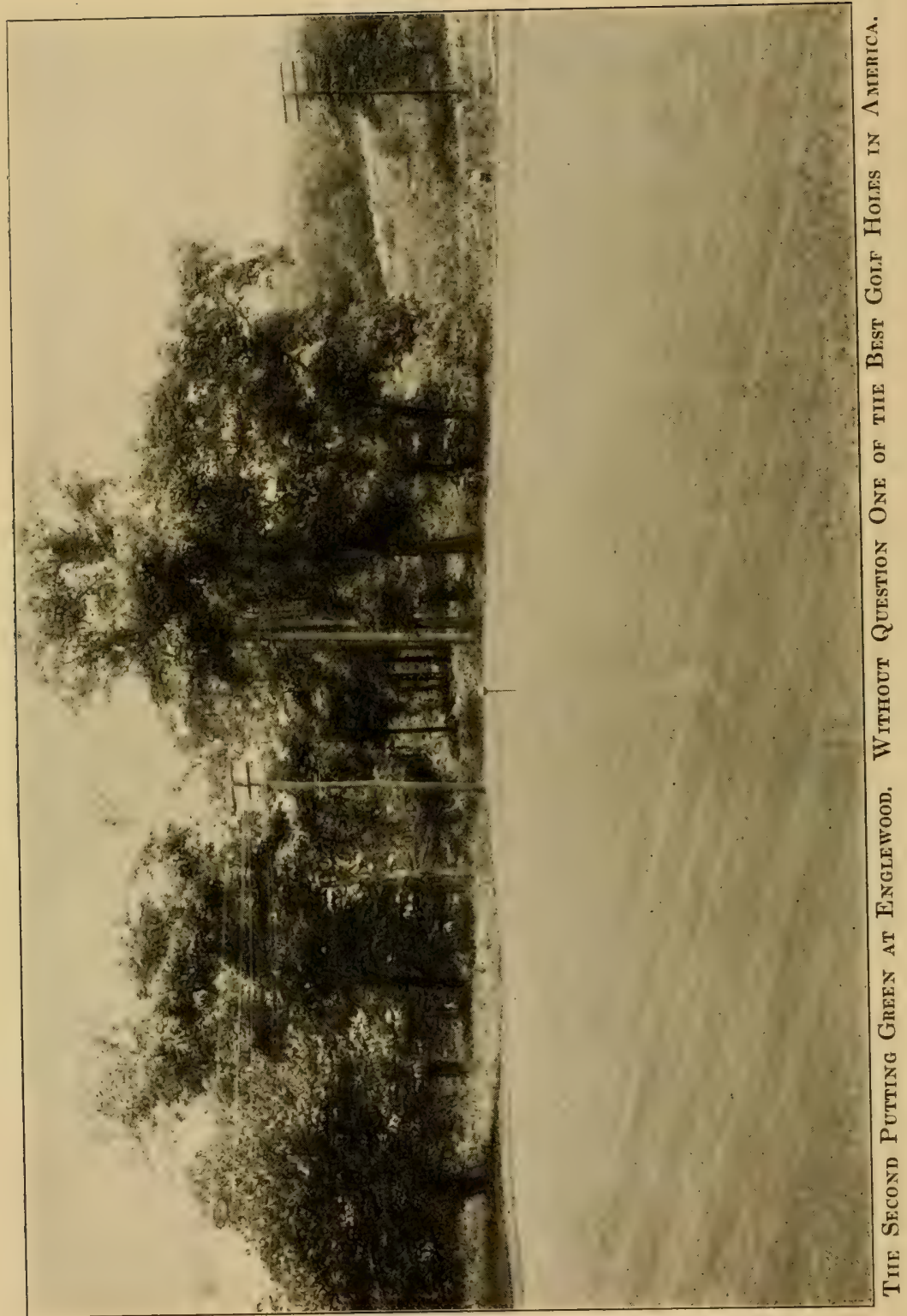


After the first clipping the lawn may be clipped closely with the lawn mower and frequent cuttings will prove beneficial. If clipped frequently and the grass kept at a height of from one and one-half to two inches, clippings will be so fine that it will not be necessary to rake them off. It is particularly desirable to leave these fine clippings on poor or light soils: on rich moist soils, the clippings may be removed by having a grass catcher attached to the lawn mower. This obviates the necessity of removing the clippings by raking.

During the extreme hot weather of mid-summer, do not crop the grass too close. Burning of the roots may be in a measure prevented by allowing the grass to shade itself.

Lawns should be rolled each spring as soon as the excess of moisture has dried out. A heavy roller is preferable, so that any grass roots that have been loosened by frost may be imbedded in the soil. The roller should be used after every cutting, as its continued use makes a firm and compact sod.

Watering of lawns should preferably be done late in the afternoon or at night; thus preventing the immediate evaporation of the water by the intense heat from the sun. Many lawns are seriously injured by frequent small applications of water. It is much better to give a lawn a thorough soaking once or twice a week, than to give small waterings daily. Use plenty of water; sufficient to wet the soil at least three inches deep.

\section{Fertilizing Lawns After They Are Established.}

After a lawn is well established it should be regularly fertilized with The Coe-Mortimer Company's Country Club Golf and Lawn Fertilizer, Brand $\mathrm{A}$, at the rate of two and one-half to three lbs. per one hundred square feet. (On large areas at the rate of 1300 lbs. per acre.)

The first application should be made in the spring, as soon as the frost is well out of the ground, and the second application about the 10th of August. The fertilizer should be mixed with an equal weight of medium coarse sand and should be distributed very evenly. 


\section{GOLF COURSES.}

Putting Greens.

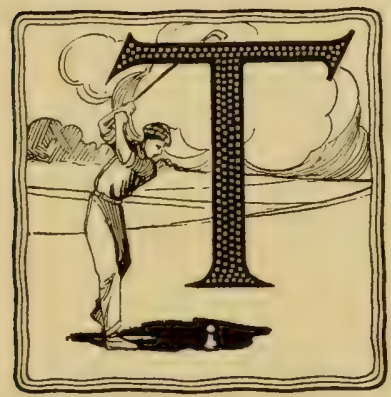

HE preparation of the soil for putting greens is in general the same as that described for lawns. Especial attention, however, should be given to the matters of draining, grading and leveling, and finally to very careful raking.

When seeding down a new putting green, use from two and one-half to three lbs. per one hundred square feet of The Coe-Mortimer Company's Country Club Golf and Lawn Fertilizer, Brand A, mixed with an equal quantity of fine sand. This should be raked into the soil shortly before sowing the seed. A sandy soil is preferable for putting greens, and if the soil is not naturally sandy, large quantities of sand must be applied.

It is necessary that the turf on a putting green should be composed of fine grasses, dense and low and sufficiently tough to stand the hardest possible use. The grass must be kept cut short and rolled with a light roller frequently. If the putting green is seeded in the spring (and it probably will be), a second application of fertilizer should be made during the latter part of June. At this time apply one and one-fourth lbs. per 100 square feet of The Coe-Mortimer Company's Country Club Golf and Lawn Fertilizer, Brand A, mixed with an equal quantity of fine or medium fine sand as before.

About the middle of August, still another application of the same fertilizer should be made at the rate of one and one-fourth lbs. per one hundred square feet of surface and as previously described, it is desirable that this fertilizer should be mixed with an equal quantity of sand. 


\section{Seed Mixtures for Putting Greens.}

Grasses of a low growing habit, of firm tough texture and those that will thrive upon acid soils are required for putting greens. A neutral or alkaline condition of the soil gives encouragement to the growth of clover which is especially to be avoided in putting greens, and it should be noted that the fertilizers recommended for putting greens, while especially

A small force feed grass seeder made especially for putting greens and lawns.

(By courtesy of The Excelsior Drill Co., Springfield, Ohio.)

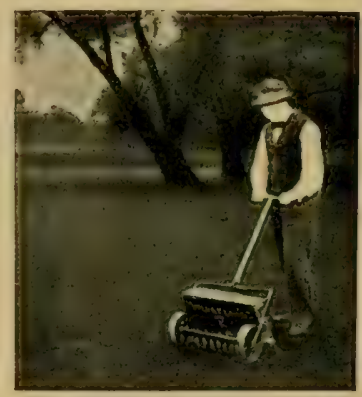

adapted to encourage the growth of the desirable grasses, are intended at the same time to discourage the growth of clovers. Probably the best mixture for putting greens is the following:

Rhode Island Bent Grass (Agrostis canina)....... $50 \mathrm{lbs}$.

Creeping Bent Grass (Agrostis stolonifera)....... $50 \mathrm{lbs}$.

Re-cleaned Redtop (Agrostis vulgaris).......... $20 \mathrm{lbs}$.

Total...................... $\overline{120} \mathrm{lbs}$.

Use this mixture at the rate of $120 \mathrm{lbs}$. per acre or at the rate of a little over one-fourth $1 \mathrm{~b}$. ( 5 ounces) per one hundred square feet.

This same grass seed mixture should be used for all re-seeding. When re-seeding is needed on account of bare spots or weak growth of grass it should be done early in the spring; about a week after the first application of fertilizer. Rake in thoroughly with a fine rake and roll immediately after with a heavy roller. 


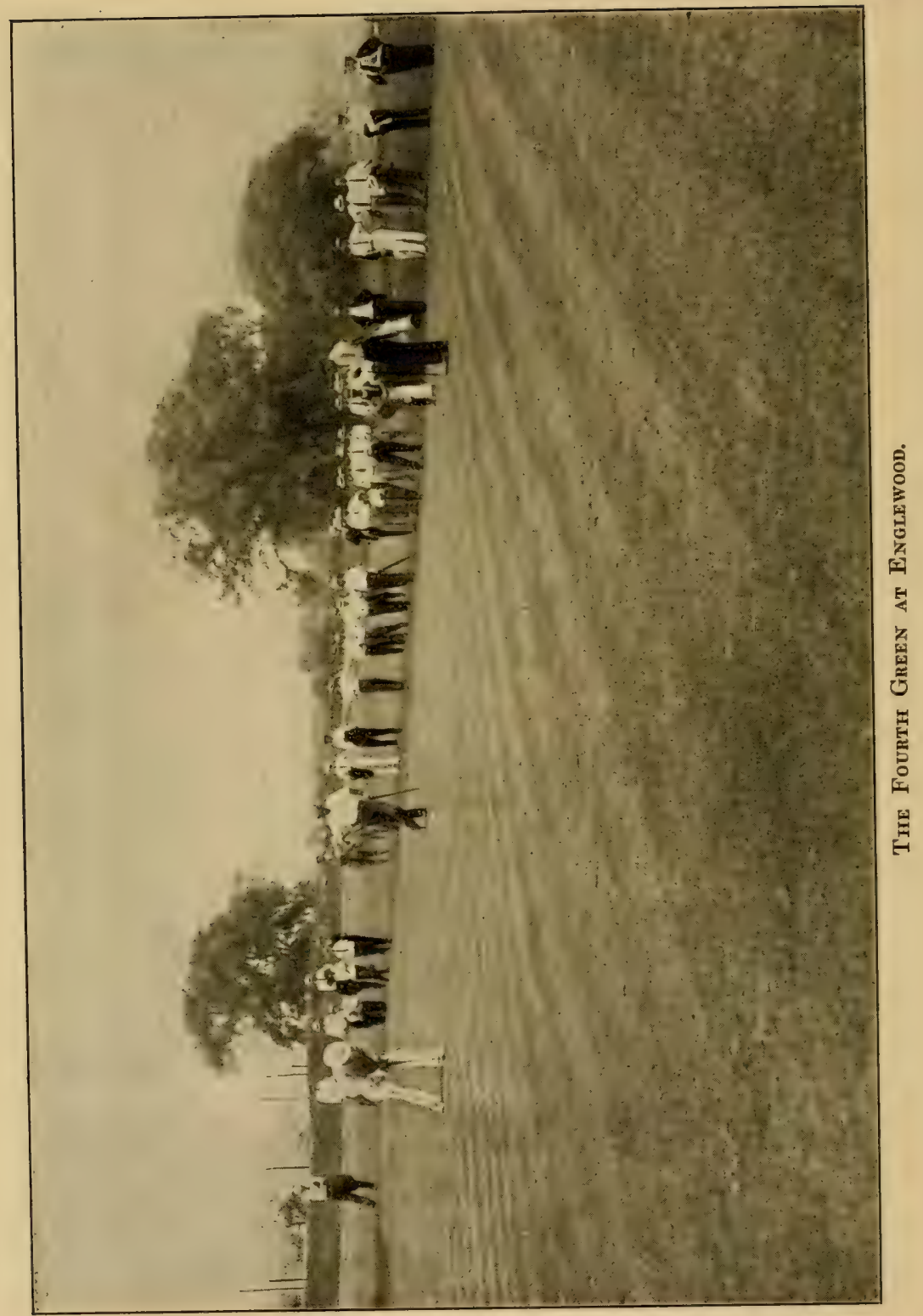


If further re-seeding is necessary and it generally is, in order to keep the greens up in first class condition, sow the seed the last week in August or the first week in September. Fall seeding may be regarded as even more important than the spring seeding. It should be raked in with a very fine rake, and the roller should follow immediately.

"Golf Cart" an extremely useful combination of roller and cart body.

(By courtesy of The Excelsior Drill Co., Springfield, Ohio.)

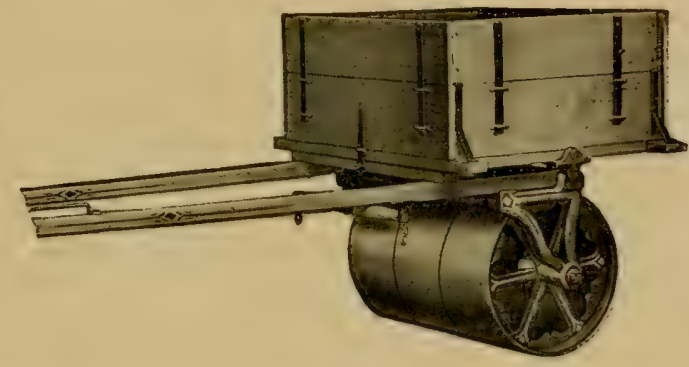

\section{General Care of Putting Greens.}

In addition to close clipping, frequent rolling and thorough watering, especial attention is called to the importance of top dressing the greens at least three times each season as mentioned above. Never use stable manure of any sort on a putting green. It is sure to introduce quantities of weed seeds and is almost certain to kill out the grass in spots. In addition to this it is extremely unsightly and further injures the playing qualities of the greens.

The Coe-Mortimer Company's Country Club Golf and Lawn Fertilizer, Brand A, is especially adapted for use upon putting greens and its proper use gives results that are encouraging and demonstrates that as good greens can be developed in the United States as in Great Britain.

\section{Sanding the Greens.}

Medium to fine sand should be applied to the depth of one-fourth inch over the entire surface of the putting greens, during the latter part of December or early in January. It 
is desirable to apply this sand after the ground is frozen but before there has been a fall of snow. Do not apply any soil or loam as a surface dressing, using clean sand exclusively.

\section{Eradication of Worms.}

It is extremely annoying to have the putting greens disfigured by unsightly worm casts and the playing qualities of the greens are also impaired by them. To eradicate angle worms, use The Coe-Mortimer Company's Country Club Worm Eradicator at the rate of one-half $\mathrm{lb}$. per square yard. The Worm Eradicator should be applied evenly over the putting greens and the greens flooded with water. The Worm Eradicator is most effective when used on a warm damp day. After the flooding the worms will come to the surface where they may be raked up, or swept up and removed. One application of the Worm Eradicator in the spring should prove sufficient to keep the greens free from worms throughout the summer.

Unlike many preparations for eradicating worms, our Country Club Worm Eradicator is not poisonous for human beings, although hardly pleasant to the taste. It does not burn the grass plants, even when used in much larger quantities than recommended above. We have recommended one-half $\mathrm{lb}$. per square yard of the Country Club Worm Eradicator as an economical quantity that will give good results; but as the Worm Eradicator also enriches the soil and encourages the growth of the grass, a larger application may at times prove desirable.

\section{Watering.}

Putting greens should never be allowed to burn out in dry weather. The general remarks concerning watering lawns apply also to putting greens, except that as the greens are kept clipped very close, it is necessary to be sure that the waterings penetrate to a good depth. Watering once or twice a week, thoroughly, and to a good depth is to be preferred to a light sprinkling every day. 


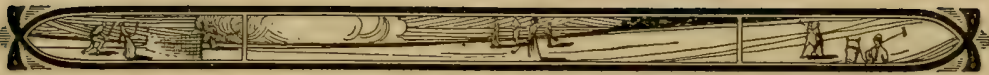

\section{Fair Greens.}

Two problems are commonly presented in regard to fair greens. First, the improvement of old greens without plowing; second, plowing and establishment of new greens.

In renovating old greens, first remove all stones, twigs, sticks, dead grass, etc., and thén go over the greens with a perforating roller, such as is illustrated herein. If clover is not objected to in the fair greens, the mechanical condition of the soil may be greatly improved and at the same time the land be greatly enriched by broadcasting 1300 lbs. per acre of The Coe-Mortimer Company's Country Club Golf and Lawn Fertilizer, Brand B. This fertilizer is entirely unlike the Country Club Golf and Lawn Fertilizer, Brand A, as Brand B encourages the growth of clovers as well as the growth of grasses, while Brand $\mathrm{A}$ is suited to the development of grasses only.

If clover is an objection in the fair greens, broadcast 1300 lbs. per acre of The Coe-Mortimer Company's Country Club Golf and Lawn Fertilizer, Brand A. This should be applied after the land has been treated with the spike toothed roller and following this application the fair greens should be gone over with a cutaway disc harrow with the dises set practically straight, so that they may have a slicing action and not a digging action.

Combination seeder and weeder. A convenient implement for seeding fair greens.

(By courtesy of The Eureka Mower Company, Utica, N. Y.)

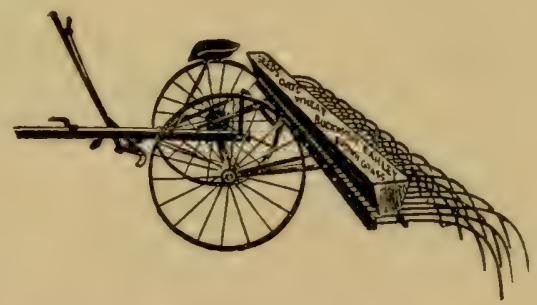

Follow this with a thorough scarifying, by means of an ordinary spring tooth weeder and then broadcast evenly one of the grass seed mixtures given on page 19. After distribut- 


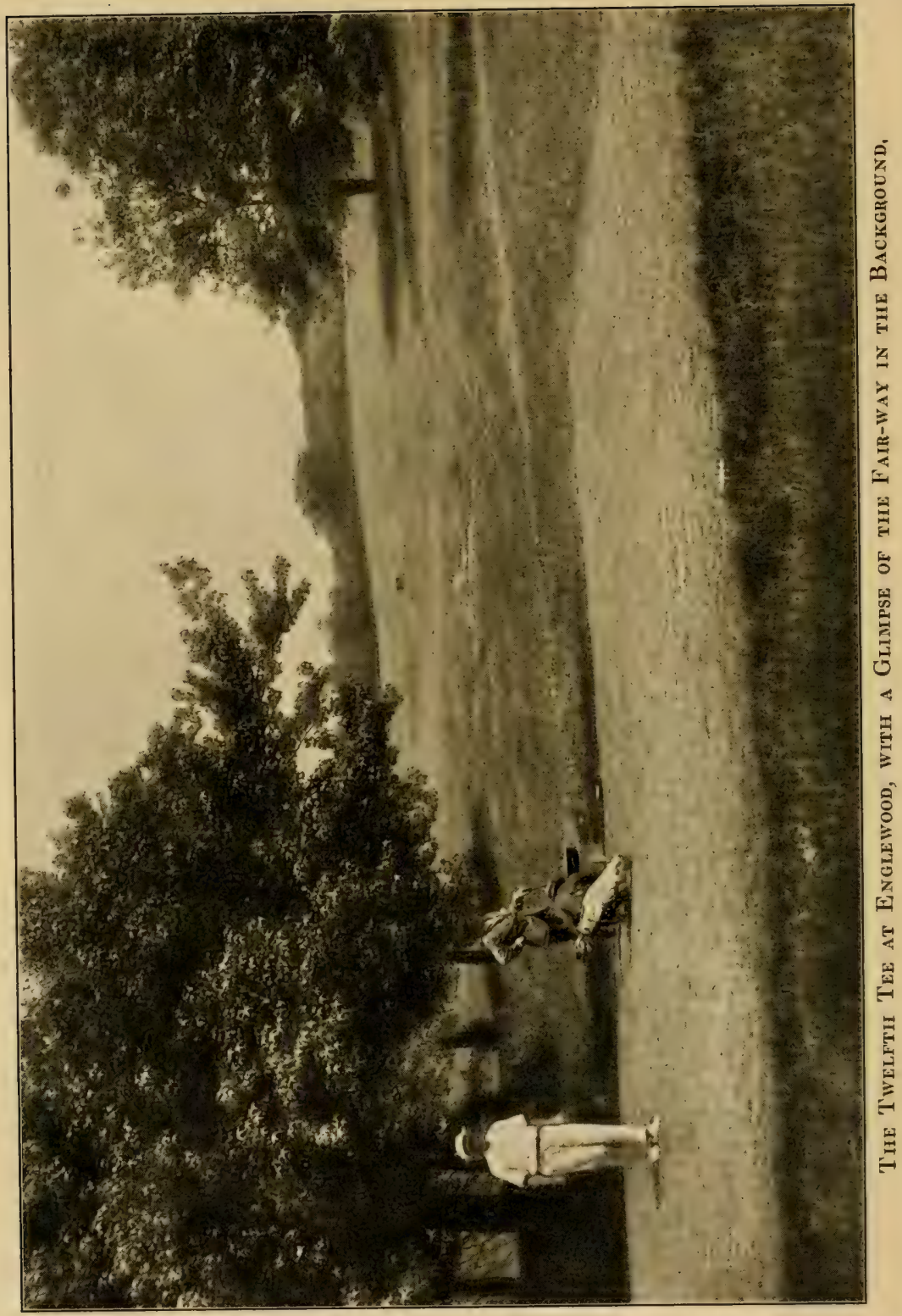


ing the grass seed, go over the greens again with the weeder to thoroughly incorporate the seed, then roll thoroughly with a heavy roller, which for this purpose should have no spike tooth attachment.

\section{New Fair Greens.}

If new fair greens are to be established, follow the same general directions as given for the preparation of lawns, but in seeding down, bear in mind that The Coe-Mortimer Company's Country Club Golf and Lawn Fertilizer, Brand A, should be used when clover is not desired and that the Country Club Golf and Lawn Fertilizer, Brand B, should be used when clover is desired. The objection to clover of course is its more or less slippery character. The advantage claimed for it is that it remains green and presents an attractive appearance if clipped close, even through extremely dry weather.

1300 to $1500 \mathrm{lbs}$. per acre of one of the above fertilizers should be well worked into the soil as directed under Preparation of Lawns. The directions there given for distributing and working the seed into the soil apply equally well to fair greens.

\section{Grass Seed Mixtures for Fair Greens.}

First, a mixture where clover is desired.

Kentucky Blue Grass (Poa pratensis) ......... $30 \mathrm{lbs}$.

Re-cleaned Redtop (Agrostis vulgaris) ............. $40 \mathrm{lbs}$.

Rhode Island Bent Grass (Agrostis canina)......... 10 lbs.

Creeping Bent Grass (Agrostis stolonifera)........ $10 \mathrm{lbs}$.

White Clover (Trifolium repens) ............... $10 \mathrm{lbs}$.

Total, per acre............... $\overline{100} \mathrm{lbs}$.

Second, a mixture where clover is not desired.

Re-cleaned Redtop (Agrostis vulgaris) .......... 40 lbs.

Creeping Bent Grass (Agrostis stolonifera)........ $20 \mathrm{lbs}$.

Rhode Island Bent Grass (Agrostis canina) ........ 20 lbs.

Kentucky Blue Grass (Poa pratensis).......... $10 \mathrm{lbs}$.

Canadian Blue Grass (Poa compressa).......... $10 \mathrm{lbs}$.

Total, per acre................ $\overline{100}$ lbs. 


\section{Subsequent Care of Fair Greens.}

Whether the work in hand is the renovation of old greens or the making of new greens, 500 lbs. per acre of The CoeMortimer Company's C'ountry Club Golf and Lawn Fertilizer, Brand A, or Brand B (as indicated by conditions) should be applied about the first of 'September of the first season. Each subsequent year, 1,000 lbs. per acre of one of the above fertilizers should be applied in the spring, as soon as the frost is well out of the ground. The second application in September, will probably not be required after the first year; though on the fair greens, if the growth of the grass is insufficient, indicating lack of plant food, an application of 500 lbs. per acre of one of the Country Club Fertilizers should be made about the first of September.

Both spring and fall applications of the fertilizer should be mixed with an equal weight of medium sand. 'The grass should be kept well rolled and clipped during the entire season. 


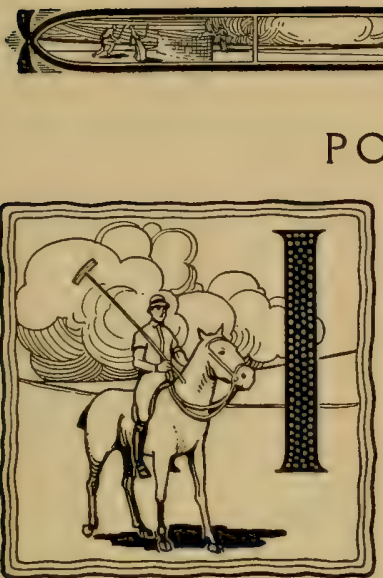

\section{POLO FIELDS.}

is generally desirable for polo fields.

N MAKING a polo field, special emphasis should be laid upon drainage, leveling and grading. A competent engineer should be employed to make "assurance doubly sure" concerning these points. The general directions given for plowing and fitting the soil for lawns, apply also to polo fields, except that in addition to the work indicated for lawns, sub-soil plowing

After plowing with the turning plow, follow in the same furrows with the sub-soil plow; the object being to loosen the sub-soil without bringing any of it to the surface. In sub-soil plowing, however, great care must be taken not to disturb any drains that may have been laid near the surface of the field.

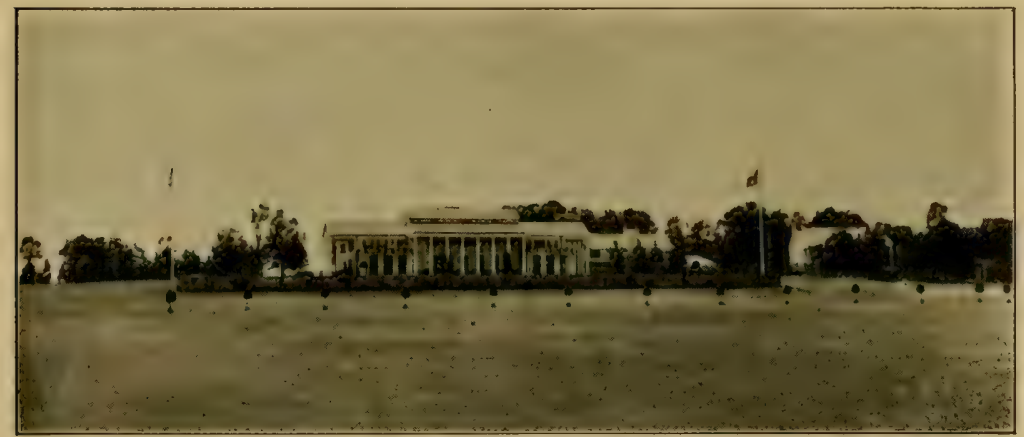

The Club House at the Piping Rock Club, Locust Valiex, L. I.

Special precautions should be observed in harrowing, to be sure that the ground is finely pulverized and that all old growth is entirely killed out. Mid-summer seeding, about August 15th to September 1st is generally preferable, as this 
gives ample time during the early part of the season for thorough preparation of the land.

In seeding down a new polo field, apply 1500 lbs. per acre of The Coe-Mortimer Company's Country Club Golf and Lawn Fertilizer, Brand A. This should be worked into the soil thoroughly with the cutaway disc harrow and great pains should be taken to see that the fertilizer is distributed evenly.

The grass seed may be distributed either by hand or by means of a combination weeder and seeder, such as is illustrated herein. After the seed has been distributed and thoroughly worked into the soil, the field should of course be rolled repeatedly with a heavy roller.

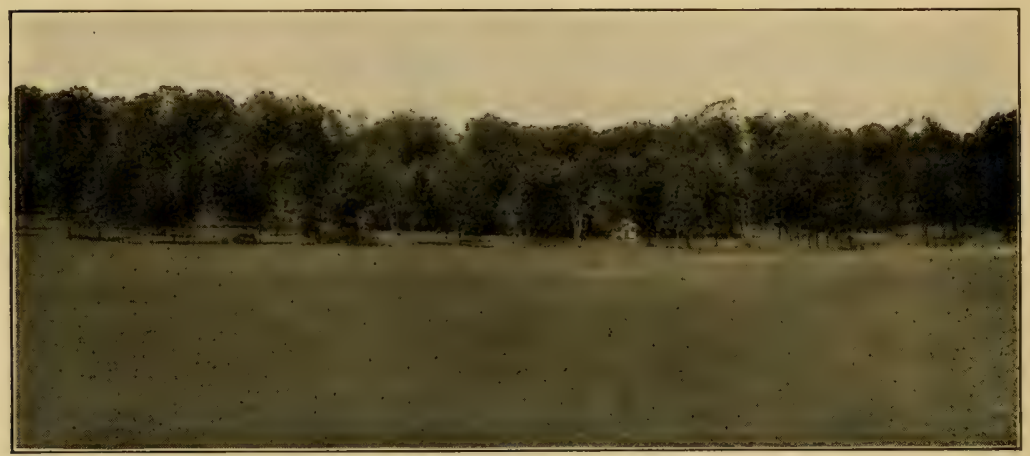

Looking across the Polo Fields at the Piping Rock Club, Locust Valley, L. I.

Subsequent treatment of the polo field consists of the application of $700 \mathrm{lbs}$. per acre of Country Club Golf and Lawn Fertilizer, Brand A, the last week in June, and the application of a similar amount of the same fertilizer about the middle of August. In both cases the fertilizer should be mixed with an equal weight of medium sand.

Old polo fields should be treated as follows: As soon as the frost is out of the ground in the spring, apply 1,000 lbs. per acre of The Coe-Mortimer Company's Country Club Golf and Lawn Fertilizer, Brand A, mixed with an equal quantity 
of medium sand. The last week in June, apply the same fertilizer at the rate of 600 lbs. per acre, mixed with an equal weight of sand.

When the soil on old polo fields is badly compacted, great benefit will be derived from the use of the perforating roller, similar to the one herein illustrated. This serves to perforate

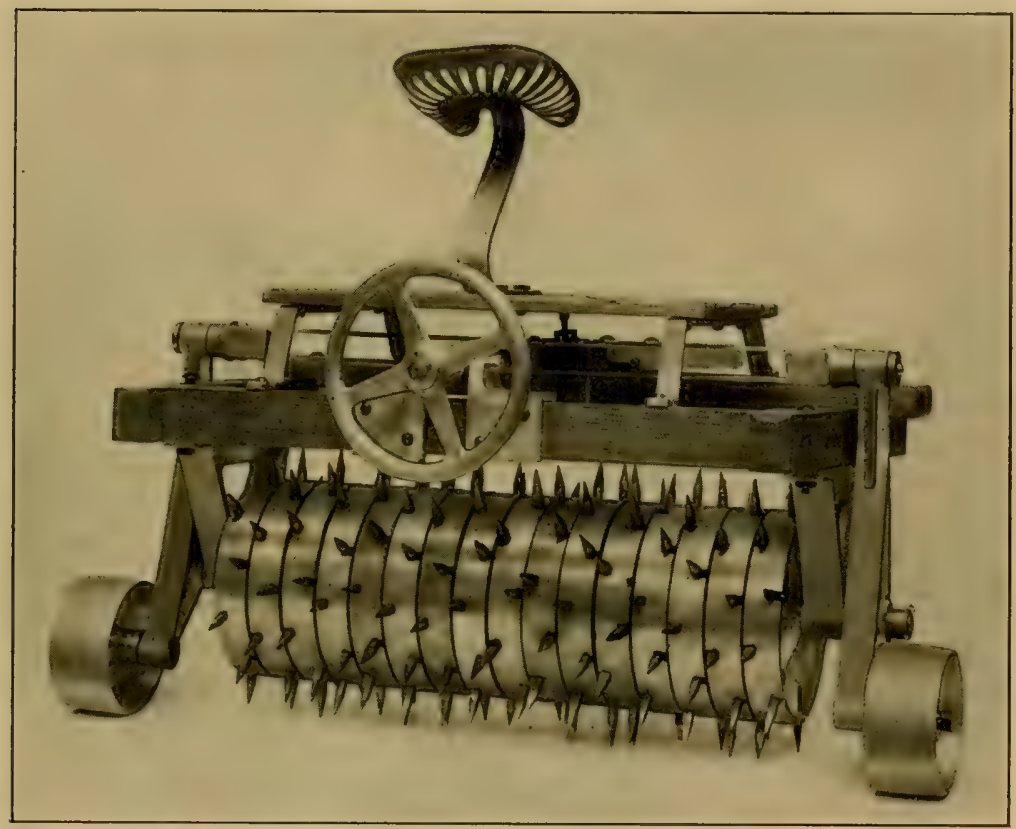

Perforating Roller for Fair Greens, Polo Fields and Lawns. The depth of perforation is regulated accurately.

(By courtesy of R. W. Whitehurst Company, Norfolk, Va.)

the sod and permits circulation of both air and water in the soil, and prevents the hard baked and caked condition that is so objectionable on a good playing field.

Supplementary seeding at the rate of from 60 to $80 \mathrm{lbs}$. per acre, of the grass seed mixture mentioned on page 25, will 


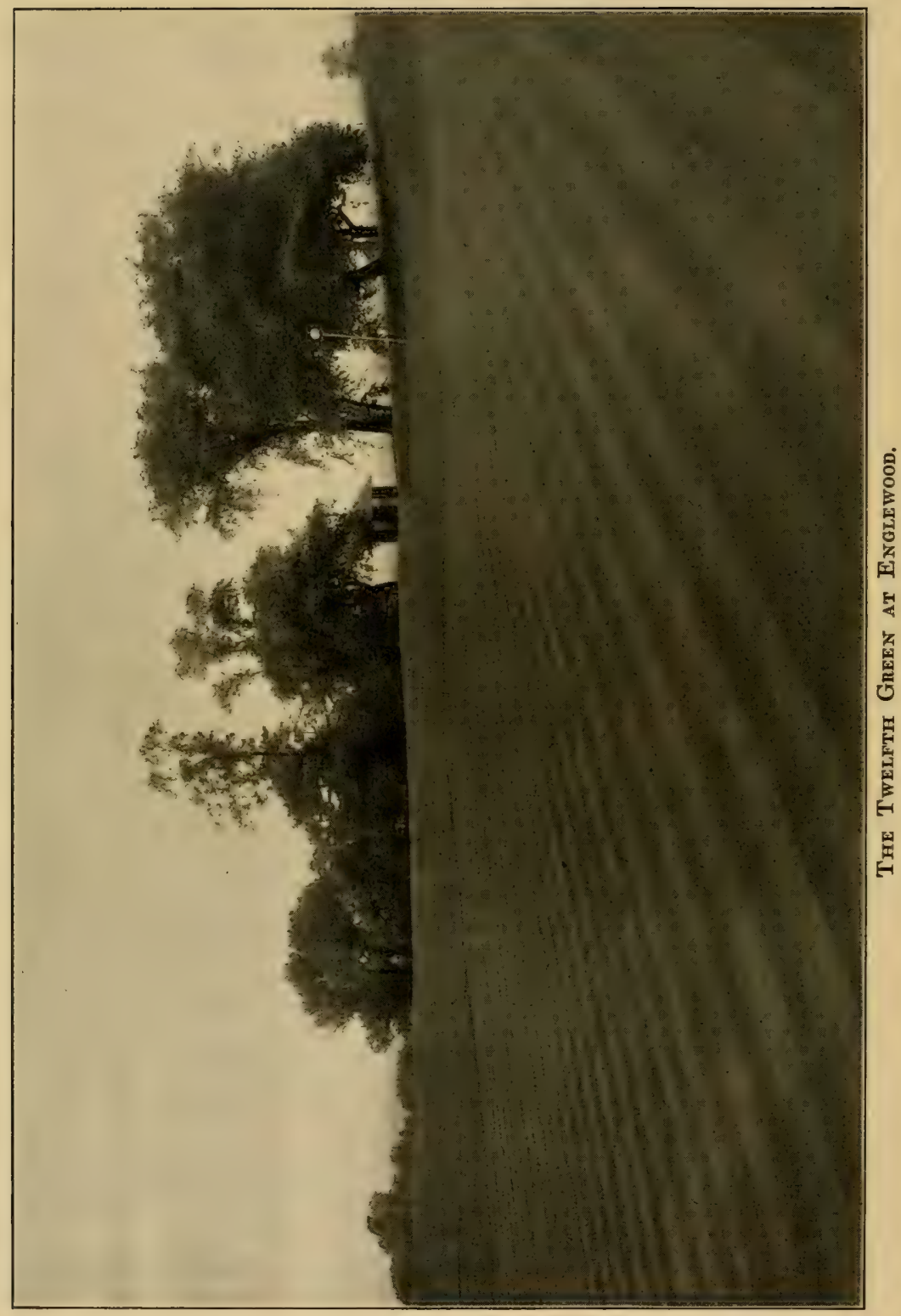


be found helpful, especially on bare and weak spots. Customary care in regard to replacing sods that have been torn up in play, and customary frequent rolling should of course receive careful attention.

About the middle of August apply the same fertilizer again, at the rate of $600 \mathrm{lbs}$. per acre mixed with an equal weight of medium sand. The grass on polo fields should be cut close and rolled frequently with a heavy roller. Polo fields in general will be benefited by an application of about onefourth inch of fine to medium sand during the latter part of December or early in January.

\section{Grass Seeds for Polo Fields.}

It is absolutely necessary that the turf on a polo field should be both tough and elastic. It is also necessary that clover should be excluded, as during dry weather, when the fields are apt to become hard, clover gives a slippery surface.

The Country Club Golf and Lawn Fertilizer, Brand A, recommended above for polo fields is specially made to discourage the growth of clover.

It is also important to avoid the use of lime on land intended for polo fields. Quick lime, hydrated lime, carbonate of lime, wood ashes and ground bone are all objectionable, because they encourage the growth of clover.

The following combination of grass seeds gives a firm, tough and elastic sod and these grasses are especially benefited by the use of the Country Club Golf and Lawn Fertilizer, Brand A.

Re-cleaned Redtop (Agrostis vulgaris)......... 50 lbs.

Rhode Island Bent Grass (Agrostis canina)...... 50 lbs.

Creeping Bent Grass (Agrostis stolonifera)....... $20 \mathrm{lbs}$.

Total.................. $\overline{120}$ Ibs.

This is the correct quantity for one acre and should be distributed evenly. 


\section{Eradication of Clover.}

In cases where polo fields have become infested with clover, especially vigorous measures are necessary to discourage its growth. In such cases we recommend The Coe-Mortimer Company's Polo Field Special, to be applied, 1,000 lbs. per acre early in the spring, as soon as the frost is well out of the ground and 1,000 lbs. per acre late in August. The fertilizer should be mixed with an equal weight of sand in both cases and distributed evenly.

When the Country Club Polo Field Special is used, no other fertilizer should be employed. Once clover is established, its eradication is at best a slow process, but by the persistent use of the Country Club Polo Field Special, the desired effect will ultimately be obtained.

This fertilizer is so made as to discourage the growth of clover and at the same time to encourage the growth of such grasses as Redtop, Rhode Island Bent Grass and Creeping Bent Grass, all of which will thrive under its application. This is a very powerful and concentrated fertilizer and special care should be taken to emphasize the necessity for even distribution.

\section{TURF TENNIS COURTS.}

The instructions given for the preparation of lawns and putting greens apply to the preparation of turf tennis courts. New courts should receive three lbs. per one hundred square feet of The Coe-Mortimer Company's Country Club Golf and Lawn Fertilizer, Brand A, prior to seeding. The fertilizer should be mixed with fine sand and thoroughly worked into the soil.

Later in the season, about the middle of June, apply The Coe-Mortimer Company's Country Club Golf and Lawn Fertilizer, Brand $A$, at the rate of one and one-fourth lbs. per one hundred square feet. Late in August repeat this treatment.

Old turf courts should receive three lbs. per one hundred square feet of surface of Country Club Golf and Lawn Fertilizer, Brand A, as soon as the frost is out of the ground 
and should receive the same applications in June and in August as mentioned above. On old courts the spring application should be mixed with an equal weight of fine sand, as should the two later applications. Close clipping, frequent rolling and watering are essential to good courts.

\section{Grass Seed for Turf Tennis Courts.}

A fine, close springy turf is the prime essential and under average conditions is best obtained by using the following mixture:

Rhode Island Bent Grass ( $\Lambda$ grostis canina)...... $40 \mathrm{lbs}$.

Creeping Bent Grass (Agrostis stolonifera)....... 50 los.

Re-cleaned Redtop (Agrostis vulgaris)......... 30 lbs.

Total...................... $\overline{120} \mathrm{lbs}$.

This indicates the quantity to be used for one acre, and smaller areas should be seeded in the same proportion.

\section{Fertilizers for Lawns, Golf Courses and Polo Fields.}

To produce and maintain a fine elastic turf of uniform color and even texture requires fertilizers made with especial care. Comparatively few of the lawn fertilizers that have heretofore been offered have been prepared with due regard to the special problems presented. Unlike fertilizers for hay, the fertilizers for lawns must contain plant food in forms that are not only available to the plants, but also in forms that extend this available action over a considerable period of time.

In other words, correctly made lawn fertilizers should feed the grass plants gradually but constantly. There must be no intermittent period when the grass plants do not receive suitable nourishment.

For six years past The Coe-Mortimer Company has been making Country Club Golf, Lawn and Polo Field Fertilizers for a select private trade. These fertilizers are made in accordance with the formulæ of the Chairman of the Green 


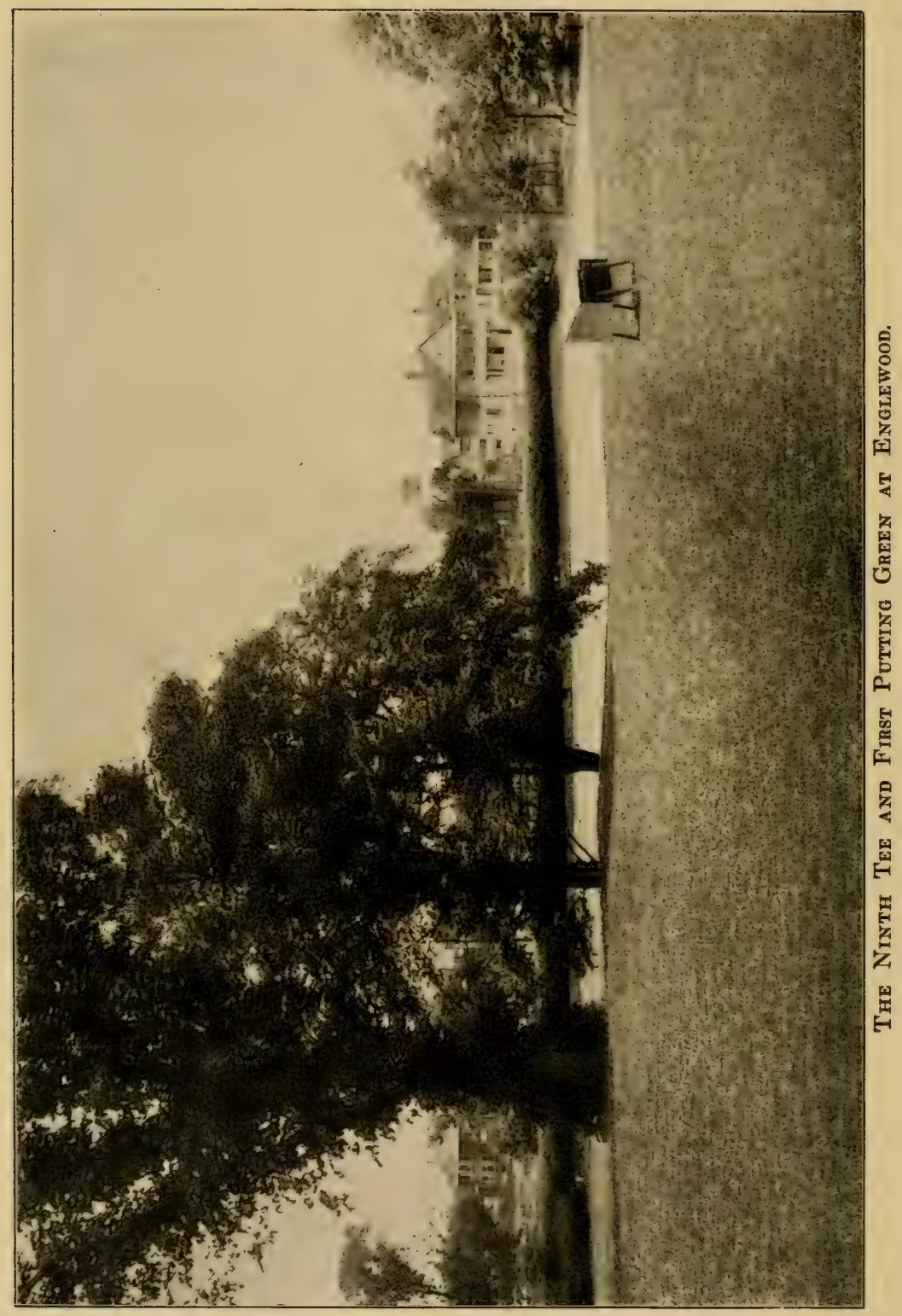


Committee of the Englewood Golf Club, Mr. S. A. Cunningham, who has perfected Country Club brands, after many years of experimental work.

Associated with Mr. Cumningham in the development and preparation of these fertilizers, is $\mathbf{M r}$. George D. Leavens, formerly of the Massachusetts State Experiment Station and for over fifteen years a specialist in grass fertilization.

The results from the use of Country Club brands have - been uniformly superior and the demand for them has become increasingly urgent. They are now offered generally to those buyers who realize that fertilizers of high quality are absolutely essential to the growing of good grass.

For many years stable manure was highly regarded as a lawn dressing. The objections to its use are however, obvious. When it is used as a top dressing the lawns so treated resemble a barnyard for several months each year. Large quantities of weed seeds are introduced by the stable manure and these weeds can be gotten rid of only at a great expense.

Furthermore many grass plants are frequently smothered and killed out by small lumps of manure. This results in the lawn having a spotted or uneven appearance.

Said the late Luke J. Doogue, for many years Superintendent of the Boston Public Grounds Department: "Strange as it may seem, many good lawns have been ruined by being given a heavy application of manure year after year." Country Club Golf, Lawn and Polo Field Fertilizers are offered to discriminating buyers as being the highest grade fertilizers obtainable for the purposes indicated.

\section{Country Club Golf and Lawn Fertilizer, Brand A.}

This special fertilizer is specially manufactured for use upon lawns, putting greens, polo fields, fair greens and tennis courts where clover and blue grass are not desired. The same soil conditions that favor the development of clover also faror the development of blue grass and while blue grass in itself may be desirable for certain purposes, it should be constantly borne in mind that if the soil is so treated as to encourage 
the growth of blue grass, then the risk of encouraging an abnormal growth of clover will be very great.

Clover seed will lie dormant in the soil for from 25 to 40 years waiting for favorable conditions to cause its germination and growth. Inasmuch as perfect lawns, polo fields, putting greens and grass tennis courts can be made without the use of blue grass or clover, it is apparent that Country Club Golf and Lawn Fertilizer, Brand A, possesses a wide range of usefulness.

It encourages the growth of Redtop, Creeping Bent Grass, Rhode Island Bent Grass, and all grasses belonging to this family, feeding them abundantly and continuously, at the same time discouraging the growth of clover.

\section{Country Club Golf and Lawn Fertilizer, Brand B.}

This special fertilizer is intended for use upon, lawns and fair greens where clover and blue grass are desired. It should never be used upon putting greens or polo fields or upon grass tennis courts, as the presence of clover in any of these is always objectionable.

There are, however, occasions when individual taste or preference call for lawns containing a large amount of fine white clover. Also there are occasions when clover is desired in fair greens, particularly on extremely light and dry soils. Country Club Golf and Lawn Fertilizer, Brand B, will encourage the growth of clover and also encourage the growth of Kentucky Blue Grass and is intended to be used only when these results are desired.

\section{Country Club Polo Field Special.}

As indicated above, Country Club Golf and Lawn Fertilizer, Brand $\mathrm{A}$, is the correct fertilizer to use on polo fields under normal conditions. In cases where polo fields are already badly infested with clover, more radical treatment may be necessary.

When polo fields contain a large amount of clover, the Country Club Polo Field Special Fertilizer should be used. 
This brand is so made as to act even more vigorously than the Golf and Lawn Fertilizer, Brand A, and brings about soil conditions extremely unfavorable to the growth of clover and also greatly encourages the growth of the fine and tough grasses, thus aiding these to choke out the clover.

For special directions for use, see remarks on "Eradication of Clover."

\section{Country Club Worm Eradicator.}

Frequently, common earth worms or "angle worms" become a decided nuisance in lawns or putting greens. Not only do the worm casts disfigure the greens, but they also injure the playing qualities.

To rid greens or lawns of worms, apply Country Club Worm Eradicator at the rate of one-half pound per square yard, spreading evenly over the green and then flooding the green with water. If possible the application should be made on a warm damp day early in May. The worms will come to the surface where they may be raked up or swept up and removed. One application each season is usually sufficient, but should the worms again become troublesome, a second application may be made about the middle of September.

Especial attention is called to the fact that Country Club Worm Eradicator is non-poisonous to human beings, and is decidedly beneficial to the grass. It has a direct but slow fertilizing action which adds materially to its value.

It is well to bear in mind that in purchasing Country Club Golf, Lawn and Polo Field Fertilizers, you are securing fertilizers that have been thoroughly and repeatedly tested and have proved their merit by the results that they have given. All experimental work has been done for you.

Combining as they do, the latest teachings of agricultural science with long practical experience, these fertilizers cannot fail to meet with your appreciation and approval. 
100 . 


$$
\text { . }
$$


${ }^{5}$

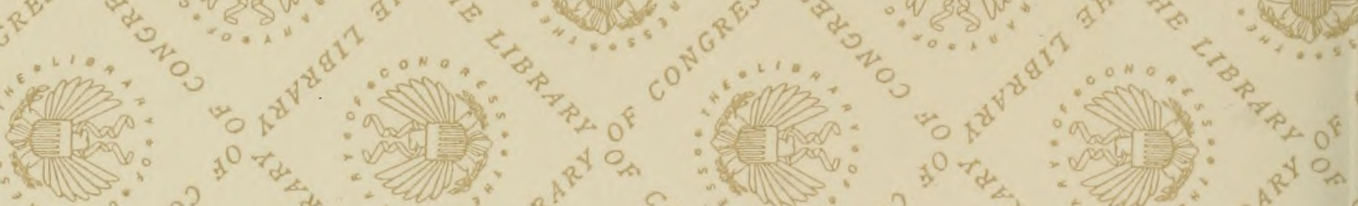
a. (3)

a

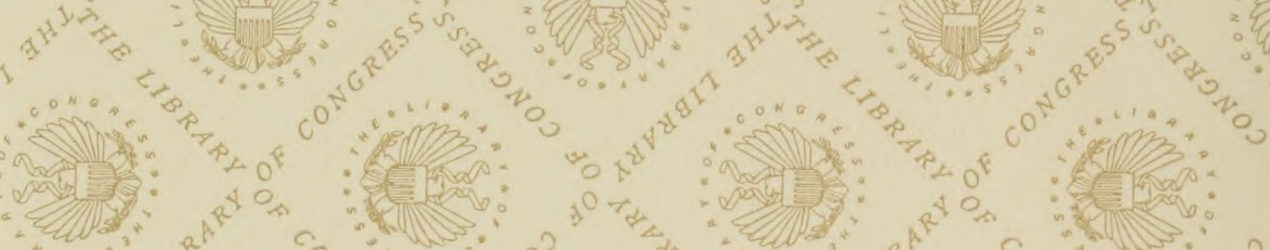
and

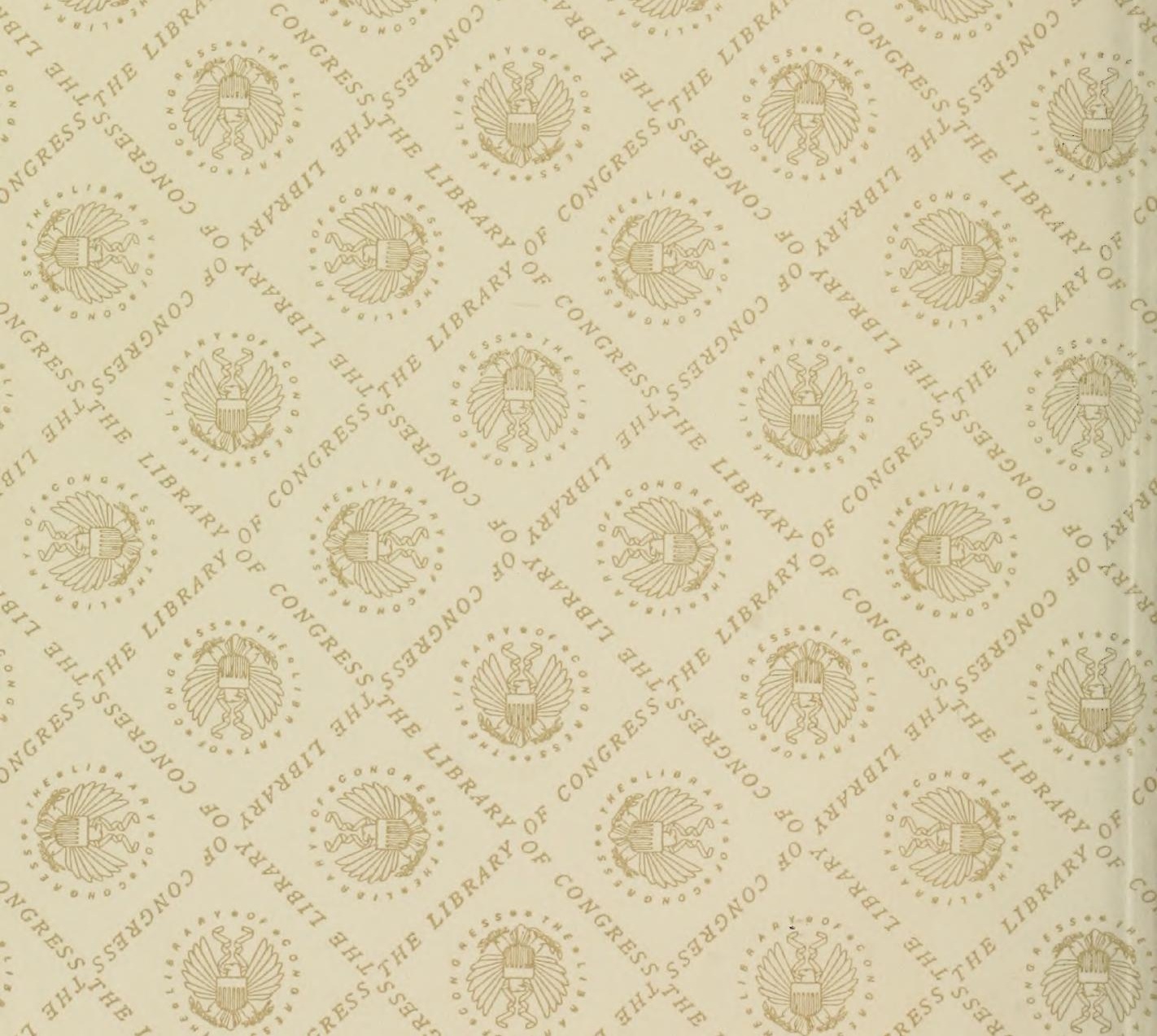




\section{LIBRARY OF CONGRESS |||||||||||||||||||||||||||||||||||||||||||||||||||| 00009250785}

